\title{
Bidirectional Radio-Over-Fiber System With Phase-Modulation Downlink and RF Oscillator-Free Uplink Using a Reflective SOA
}

\author{
Yu, Xianbin; Gibbon, Timothy Braidwood; Tafur Monroy, Idelfonso
}

Published in:

IEEE Photonics Technology Letters

Link to article, DOI:

10.1109/LPT.2008.2009947

Publication date:

2008

Document Version

Publisher's PDF, also known as Version of record

Link back to DTU Orbit

Citation (APA):

Yu, X., Gibbon, T. B., \& Tafur Monroy, I. (2008). Bidirectional Radio-Over-Fiber System With Phase-Modulation Downlink and RF Oscillator-Free Uplink Using a Reflective SOA. IEEE Photonics Technology Letters, 20(24), 2180-2182. https://doi.org/10.1109/LPT.2008.2009947

\section{General rights}

Copyright and moral rights for the publications made accessible in the public portal are retained by the authors and/or other copyright owners and it is a condition of accessing publications that users recognise and abide by the legal requirements associated with these rights.

- Users may download and print one copy of any publication from the public portal for the purpose of private study or research.

- You may not further distribute the material or use it for any profit-making activity or commercial gain

- You may freely distribute the URL identifying the publication in the public portal 


\title{
Bidirectional Radio-Over-Fiber System With Phase-Modulation Downlink and RF Oscillator-Free Uplink Using a Reflective SOA
}

\author{
Xianbin Yu, Timothy Braidwood Gibbon, and Idelfonso Tafur Monroy
}

\begin{abstract}
We propose and demonstrate a bidirectional radio-over-fiber (RoF) system based on a reflective semiconductor optical amplifier (RSOA). In this system, phase-modulated 5.25-GHz radio frequency ( $R F$ ) carrying $850 \mathrm{Mb} / \mathrm{s}$ is used for the downstream signal. Optical envelope detection of 10-GHz RF carrying $850 \mathrm{Mb} / \mathrm{s}$ is achieved in an RSOA. Both signals share a single fiber link and the same light source by exploiting optical carrier remodulaiton. Moreover, there is no need to employ RF down-conversion technology for RoF uplink. This makes the proposed system simpler and more cost-effective. The experimental results indicate that after simultaneous transmission of downstream and upstream signals over $25-\mathrm{km}$ fiber, the receiver sensitivities are -22 and $-14.5 \mathrm{dBm}$, respectively.
\end{abstract}

Index Terms-Convergent optical network, phase modulation, radio-frequency (RF) oscillator-free, radio-over-fiber (RoF), reflective semiconductor optical amplifier (RSOA).

\section{INTRODUCTION}

$\mathbf{R}$ ADIO-OVER-FIBER (RoF) technology is very attractive for providing wireless services to fixed and mobile users in wireless and wireline convergent optical networks. Its wellknown advantages compared to the traditional wireless communication techniques include low loss, large bandwidth, and high compatibility with electromagnetic environments [1]. This convergent network shares a homogenous infrastructure based on different types of access technologies, and paves the way to the future communication goal: a world where affordable communication is always available everywhere to everybody [2]. Therefore, a key issue in an access network is to design architecture with simple optical network units. Furthermore, the use of one single fiber for both upstream and downstream transmission is also expected to reduce network size and the connection complexity of the outside plant.

Many efforts have contributed to the study of bidirectional systems [3]-[9]. In these systems, a reflective semiconductor optical amplifier (RSOA) operating as a modulator often plays an important role [3]-[7], and both the upstream and downstream channels use the same wavelength. This is an extremely useful strategy for improving the wavelength utilization efficiency. However, in wireless access networks, expensive radio-

Manuscript received May 26, 2008; revised September 08, 2008. Current version published December 12, 2008.

The authors are with the DTU Fotonik-Department of Photonics Engineering, Technical University of Denmark, DK-2800 Kgs. Lygnby, Denmark (e-mail: xyu@com.dtu.dk).

Color versions of one or more of the figures in this letter are available online at http://ieeexplore.ieee.org.

Digital Object Identifier 10.1109/LPT.2008.2009947 frequency (RF) down-conversion technology is necessary for the traditional RoF reception method, which leads to the challenge of developing a more cost-effective bidirectional communication system. Recently, the envelope detection technique is a promising option to simplify the RoF system since no RF down-conversion is needed at the receiver compared to the conventional RoF system [10]. On the other hand, phase-modulated RoF links present several advantages over the intensity modulated links, such as no need for dc bias, better link gain, and linearity [11].

In this letter, we propose a bidirectional RoF system based on RSOA technology, employing phase modulated RoF for the downstream signal and intensity remodulated RoF for the upstream signal. In the proposed system, the upstream and downstream signals share a single fiber and the same light source. Moreover, the need to use costly RF down-conversion devices for processing the upstream RoF signal is overcome by performing envelop detection of the signal by exploiting the modulation properties of the RSOA.

\section{EXPERIMENT SETUP AND OPERATION PRINCIPLE}

The experimental setup is shown in Fig. 1. A lightwave from a $1555-\mathrm{nm}$ external cavity laser (ECL) is phase modulated at 5.25- GHz RF carrying $850-\mathrm{Mb} / \mathrm{s}$ data with word length of $2^{9}-$ 1. This downstream signal is launched into $25 \mathrm{~km}$ of standard single-mode fiber (SSMF) with a 5-dB insertion loss. A symmetrical 3-dB coupler at the fiber output is used to split the downstream signal. Half the signal proceeds to the downstream receiver, and the other half is routed to the RSOA at the upstream transmitter for wavelength reuse as the upstream signal. At the downstream receiver, the optical signal is amplified by an erbium-doped fiber amplifier (EDFA) and the EDFA noise is rejected using an optical bandpass filter (OBPF) with a 3 -dB bandwidth of $0.4 \mathrm{~nm}$. An imbalanced-path Mach-Zehnder interferometer (MZI) performs self-heterodyning to transfer the phase modulation to intensity modulation. For a more practical implementation, the losses of the MZI could be compensated by using an SOA that can be integrated into a compact module. In the experiment, the MZI used has a transfer function with period of $10.7 \mathrm{GHz}$, which can be translated into a time delay of $93.5 \mathrm{ps}$. In this case, the system achieves a best link gain when it operates at around $5.25 \mathrm{GHz}$, which coincides with a peak of the transfer function. By tuning the phase offset between the two arms of the MZI, the signal after balanced detection (shown at point A in Fig. 1) consists of both a down-converted baseband component for fixed users and higher order RF components launched into the air. In the experiment, the down-converted baseband signal 


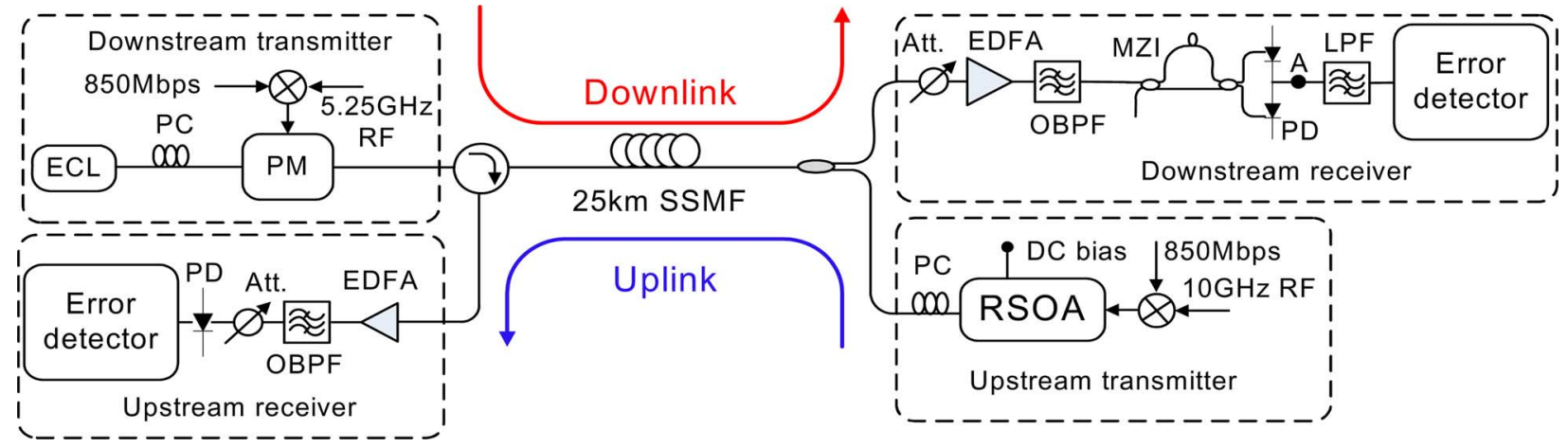

Fig. 1. Configuration of the experimental setup.

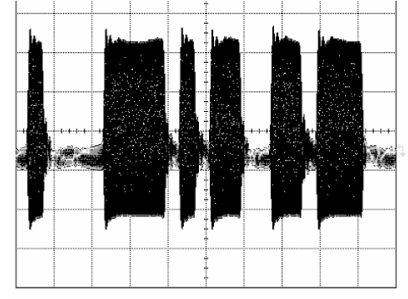

(a)

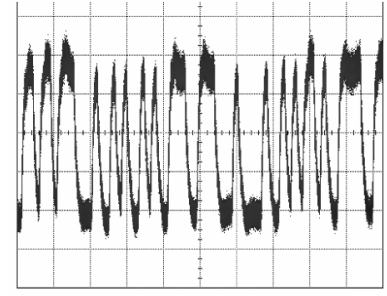

(b)
Fig. 2. Remodulation principle at RSOA. (a) Electrical 10-GHz RF carrying $850-\mathrm{Mb} / \mathrm{s}$ data driving the RSOA at the upstream transmitter. Horizontal scale: $2 \mathrm{~ns} /$ div. Vertical scale: $560 \mathrm{mV} /$ div. (b) Recovered electrical signal on a scope from driving signal (a). Horizontal scale: $5 \mathrm{~ns} /$ div. Vertical scale: $56 \mathrm{~mW} /$ div.

after a 1.8-GHz electrical low-pass filter (LPF) is fed to an error detector for bit-error-rate (BER) measurements.

At the upstream transmitter, a $10-\mathrm{GHz}$ RF signal carrying $850-\mathrm{Mb} / \mathrm{s}$ data with word length of $2^{9}-1$ is used to drive the RSOA, which is biased at $1.4-\mathrm{V}$ dc. Light from the phase-modulated downlink signal is intensity modulated and reflected by the RSOA; therefore, the downstream and upstream traffic share the same wavelength and optical source. Since the RSOA which was used in the experiment was polarization-dependent, a polarization controller (PC) is used to control the polarization state of the optical signal injected into the device. The reflective upstream signal is transmitted in the reverse direction over $25 \mathrm{~km}$ of SSMF and detected by an upstream receiver, which consists of an EDFA, OBPF, attenuator, and a photodiode.

For a modulated wireless signal, the high-frequency components which exceed the electrical bandwidth of RSOA $(1.5 \mathrm{GHz}$ in the experiment) are rejected, and hence only the digital signal within the SOA bandwidth generates the amplitude modulated upstream lightwave performing in this way optical envelope detection. Envelope detection does not restrict the upstream to only electrical amplitude modulation formats, but other modulation formats with RF frequency within the electrical bandwidth of RSOA will be preserved as well as systems with an intermediate frequency or multitones within the same bandwidth of RSOA. As shown in Fig. 2, when the $850-\mathrm{Mb} / \mathrm{s}$ bit rate at 10-GHz RF is arbitrarily selected and applied to RSOA, no RF components are observed on a scope detecting the reflective optical signal, and only the $850-\mathrm{Mb} / \mathrm{s}$ digital signal is recovered. The benefit of this is that no down-conversion devices such as local oscillator and microwave mixer are required for the uplink.

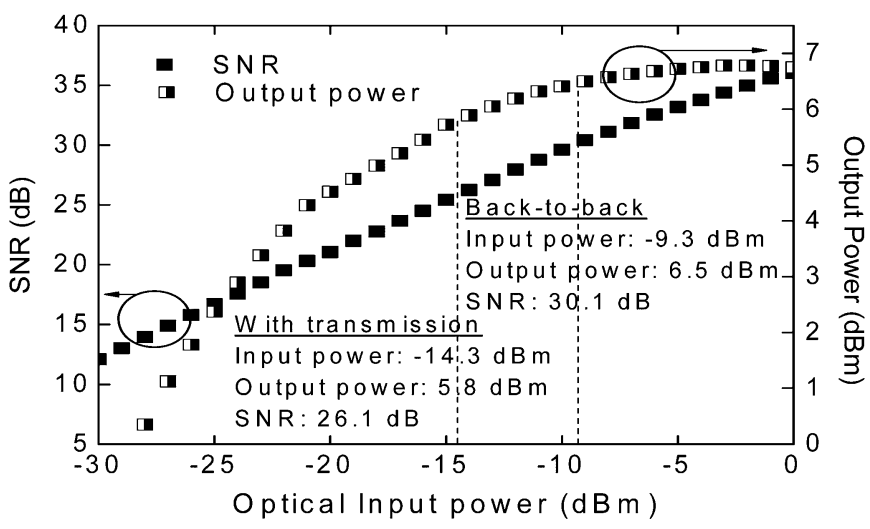

Fig. 3. Input optical power-dependent characterization of RSOA.

The output power and signal-to-noise ratio (SNR) of the reflected intensity modulated upstream optical signal from the RSOA is dependent on the average input optical power to the device. This is shown in the static characterization of Fig. 3. In order to get better modulation and improve the linearity of the RoF uplink [12], the RSOA is operated within the linear section of output power curve as well as higher SNR performance. As shown in Fig. 3, -14.3- and -9.3-dBm input optical power are injected for remodulation in the experiment. In this case, the slope between the input power and output SNR is 0.8.

\section{EXPERIMENTAL RESUlTS AND DISCUSSION}

The measured downstream BER curves before and after transmission are displayed in Fig. 4. The results both with and without the upstream signal are presented. It is evident from Fig. 4 that the back-to-back (B2B) downstream receiver sensitivity at a BER of $10^{-9}$ is around $-24.5 \mathrm{dBm}$ both with and without the upstream signal. Copropagation of the upstream signal does thus not introduce penalty for the B2B case. When the $25 \mathrm{~km}$ of SSMF fiber is inserted, the downstream receiver sensitivity without upstream transmission is found to be $-23.0 \mathrm{dBm}$. The $1.5-\mathrm{dB}$ transmission penalty introduced by the fiber is attributed to fiber dispersion that converts phase noise into intensity noise [13], thereby degrading the phase-modulated downstream RoF signal. For downstream transmission over the SSMF with copropagation of the upstream signal, the downstream receiver sensitivity is further degraded by $1 \mathrm{~dB}$ to $-22.0 \mathrm{dBm}$. This is due to interference between the upstream and downstream signals at the same 


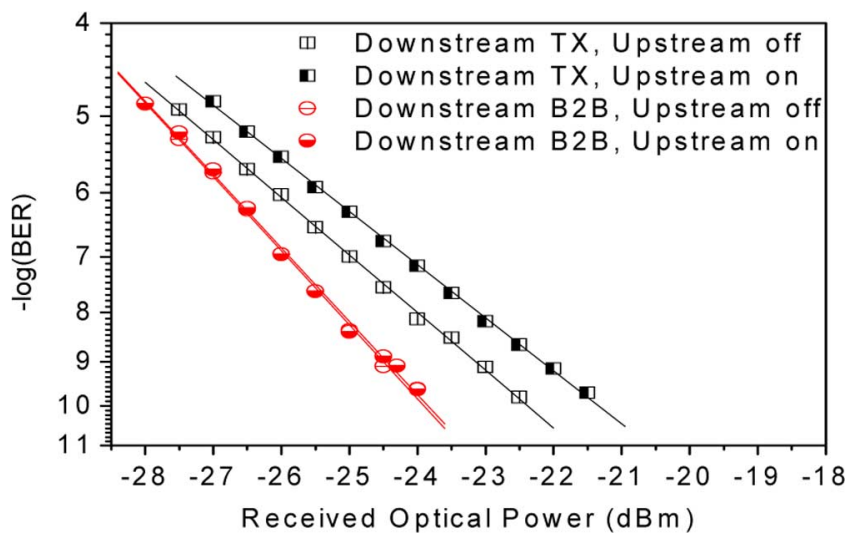

Fig. 4. Measured BER curves of the phase-modulated downstream RoF signal before and after $25-\mathrm{km}$ fiber transmission, as well as with and without copropagation of the upstream signal. TX: transmission.

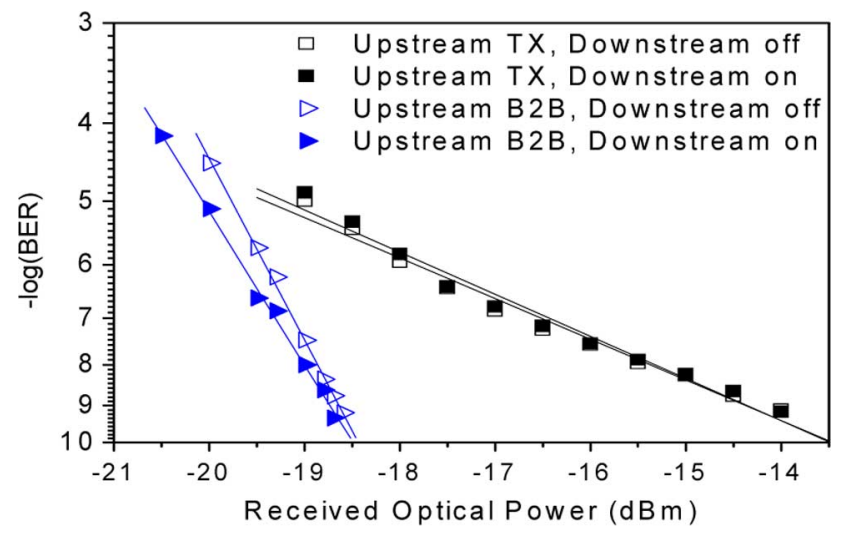

Fig. 5. Measured BER curves of the intensity modulated upstream RoF signal before and after $25-\mathrm{km}$ fiber transmission, as well as with and without copropagation of the downstream signal.

wavelength traveling in opposite directions within the same fiber. In particular, coherent interference occurs at the downstream receiver between the downstream signal and Rayleigh backscattered light from the upstream signal [14].

Fig. 5 shows BER curves of the upstream signal. It shows that both B2B links with and without copropagation of downstream signals have almost the same receiver sensitivity of $-18.7 \mathrm{dBm}$, and both transmission links with and without copropagation of downstream signals have almost the same receiver sensitivity of $-14.5 \mathrm{dBm}$. Therefore, about 4.2-dB sensitivity penalty is introduced by transmission over the $25-\mathrm{km}$ SSMF link. This penalty is introduced by Rayleigh backscattering in the fiber, which has been shown to significantly degrade bidirectional transmission performance [3], [14]. A further contributor to the penalty is SOA noise and the 5-dB loss introduced by the SSMF decreases the SNR by $4.0 \mathrm{~dB}$. As shown in Fig. 3, the SNR of upstream signal is a function of optical input power. For the lower input power the output power of the "1-bit" level is diminished, thereby lowering the extinction ratio of the remodulated upstream signal. The ultimate performance can be related to the maximum modulation bandwidth, gain and noise figure of the RSOA.

\section{CONCLUSION}

We proposed and demonstrated a bidirectional RoF system based on the use of an RSOA. A phase-modulated RoF signal and an intensity remodulated RoF signal at the RSOA are employed for downstream and upstream transmission, respectively. The experimental results show that both $850 \mathrm{Mb} / \mathrm{s}$ at $10-\mathrm{GHz}$ $\mathrm{RF}$ upstream and $850 \mathrm{Mb} / \mathrm{s}$ at $5.25-\mathrm{GHz}$ RF downstream RoF signals are error-free after $25-\mathrm{km}$ SSMF transmission. In the proposed system, both signals share the same fiber link and the same laser source. This makes this system compact. Moreover, the RSOA is cost-effective since it performs the functions of not only modulator (no need for local laser source) and amplifier, but also envelope detector, which leads to no need for RF down-conversion components. Therefore, the proposed system has potential application in next-generation convergent wireless-wireline optical network [15].

\section{REFERENCES}

[1] J. Campany and D. Novak, "Microwave photonics combines two worlds," Nature Photonics, vol. 1, pp. 319-330, Jun. 2007.

[2] J. Eberspächer, "Trends in telecommunication networking," in Managing Development and Application of Digital Technologies. Berlin Heidelberg, Germany: Springer, 2006, pp. 179-193.

[3] J. Prat, C. Arellano, V. Polo, and C. Bock, "Optical network unit based on a bidirectional reflective semiconductor optical amplifier for fiber-to-the-home networks," IEEE Photon. Technol. Lett., vol. 17, no. 1, pp. 250-252, Jan. 2005.

[4] M. D. Feuer, J. M. Wiesenfeld, J. S. Perino, C. A. Burrus, G. Raybon, S. C. Shunk, and N. K. Dutta, "Single-port laser-amplifier modulators for local access," IEEE Photon. Technol. Lett., vol. 8, no. 9, pp. 1175-1177, Sep. 1996.

[5] N. Buldawoo, S. Mottet, F. Le Gall, D. Sigonge, D. Meichenin, and S. Chelles, "A semiconductor laser amplifier-reflector for the future FTTH applications," in Proc. Eur. Conf. Opt. Commun. (ECOC 1997), Edinburgh, U.K., pp. 196-199.

[6] J. M. Kang and S. K. Han, "A novel hybrid WDM/SCM-PON sharing wavelength for up- and down-link using reflective semiconductor optical amplifier,' IEEE Photon. Technol. Lett., vol. 18, no. 3, pp. 502-504, Feb. 1, 2006.

[7] G. C. Kassar, N. Calabretta, and I. T. Monroy, "Simultaneous optical carrier and radio frequency re-modulation in radio-over-fiber systems employing reflective SOA modulators," Lasers and Electro-Optics Society (LEOS 2007), pp. 798-799, Oct. 2007.

[8] A. Kaszubowska, L. Hu, and L. P. Barry, "Remote downconversion with wavelength reuse for the radio/fiber uplink connection," IEEE Photon. Technol. Lett., vol. 18, no. 4, pp. 562-564, Feb. 15, 2006.

[9] T. Kuri, K. Kitayama, and Y. Takahashi, "A single light-source configuration for full-duplex 60-GHz-band radio-on-fiber system," IEEE Trans. Microw. Theory Tech., vol. 51, no. 2, pp. 431-439, Feb. 2003.

[10] J. Seoane, I. T. Monroy, K. Prince, and P. Jeppesen, "Local-oscillatorfree wireless-optical-wireless data link at $1.25 \mathrm{Gbit} / \mathrm{s}$ over a $40 \mathrm{GHz}$ carrier employing carrier preservation and envelope detection," in Conf. OFC/NFOEC 2008, Feb. 2008, pp. 1-3.

[11] V. J. Urick, F. Bucholtz, P. S. Devgan, J. D. Micknney, and K. J. Willams, "Phase modulation with interferometric detection as an alternative to intensity modulation with direct detection for analog-photonic links," IEEE Trans. Microw. Theory Tech., vol. 55, no. 9, pp. 1978-1985, Sep. 2007.

[12] C. H. Cox, E. I. Ackerman, G. E. Betts, and J. L. Prince, "Limits on the performance of RF-over-fiber links and their impact on device design," IEEE Trans. Microw. Theory Tech., vol. 54, no. 2, pp. 906-920, Feb. 2006.

[13] M. R. Salehi, Y. Le Guennec, and B. Cabon, "Signal and noise conversions in RF-modulated optical links," IEEE Trans. Microw. Theory Tech., vol. 52, no. 4, pp. 1302-1309, Apr. 2004.

[14] T. H. Wood, R. A. Linke, B. L. Kaspar, and E. C. Carr, "Observation of coherent Rayleigh noise in single-source bidirectional optical fiber systems," J. Lightw. Technol., vol. 6, no. 2, pp. 346-352, Feb. 1988.

[15] M. Sauer, A. Kobyakov, and J. George, "Radio over fiber for picocellular network architectures," J. Lightw. Technol., vol. 25, no. 11, pp. 3301-3320, Nov. 2007. 